\title{
Long-term evolution of continence and quality of life after sphincteroplasty for obstetric fecal incontinence
}

\author{
Vicente Pla-Martí ${ }^{1,2}$, Jose Martín-Arévaloº ${ }^{2}$ Rosa Martí-Fernández ${ }^{2}$, David Moro-Valdezate ${ }^{1,2}$, \\ Stephanie García-Botello ${ }^{1,2}$, Alejandro Espí-Macías ${ }^{1,2}$, Miguel Mínguez-Pérez ${ }^{3}$, Maria Dolores Ruiz-Carmona ${ }^{4}$ \\ Jose Vicente Roig-Vila ${ }^{5}$ \\ ${ }^{1}$ Department of Surgery, University of Valencia; ${ }^{2}$ Colorectal Unit, Department of General and Digestive Surgery, Hospital Clínico Universitario \\ de Valencia; ${ }^{3}$ Digestive Motility Unit, Department of Digestive Medicine, Hospital Clínico Universitario de Valencia; ${ }^{4}$ Department of Surgery, \\ Hospital of Sagunto; ${ }^{5}$ Colorectal Unit, Hospital Nisa 9 de Octubre, Valencia, Spain
}

Purpose: This study was performed to evaluate the long-term evolution of continence and patient's quality of life after surgical treatment for obstetric fecal incontinence.

Methods: A prospective longitudinal study was conducted including consecutive patients who underwent sphincteroplasty for severe obstetric fecal incontinence. The first phase analyzed changes in continence and impact on quality of life. The second phase studied the long-term evolution reevaluating the same group of patients 6 years later. Degree of fecal incontinence was calculated using the Cleveland Clinic Score (CCS). Quality of life assessment was carried out with the Fecal Incontinence Quality of Life scale.

Results: Thirty-five patients with median age of 55 years (range, 28 to 73 years) completed the study. Phase 1 results: after a postoperative follow-up of 30 months ( 4 to 132 months), CCS had improved significantly from a preoperative of $15.7 \pm 3.1$ to $6.1 \pm 5.0(\mathrm{P}<0.001)$. Phase 2 results: median follow-up in phase 2 was 110 months (76 to 204 months). The CCS lowered to $8.4 \pm 4.9(\mathrm{P}=0.04)$. There were no significant differences between phases 1 and 2 in terms of quality of life; lifestyle $(3.47 \pm$ 0.75 vs. $3.16 \pm 1.04)$, coping/behavior ( $3.13 \pm 0.83$ vs. $2.80 \pm 1.09$ ), depression/self-perception ( $3.65 \pm 0.80$ vs. $3.32 \pm$ $0.98)$, and embarrassment $(3.32 \pm 0.90$ vs. $3.12 \pm 1.00)$.

Conclusion: Sphincteroplasty offers good short-medium term outcomes in continence and quality of life for obstetric fecal incontinence treatment. Functional clinical results deteriorate over time but did not impact on patients' quality of life.

Keywords: Fecal incontinence; Sphincter injury; Sphincteroplasty; Quality of life

\section{INTRODUCTION}

Fecal incontinence (FI) is defined as the inability to control bowel movements, resulting in the involuntary passage of gas or stool.

Received: Jun 20, 2020 - Revised: Sep 10, 2020 - Accepted: Sep 16, 2020 Correspondence to: Vicente Pla-Martí, M.D.

Colorectal Unit, Department of General and Digestive Surgery, Hospital Clínico Universitario de Valencia, Av. de Blasco Ibáñez, 17, 46010 Valencia, Spain

Tel: +34-669204303

E-mail: vplamarti@yahoo.es

ORCID: https://orcid.org/0000-0001-7644-8416

(C) 2022 The Korean Society of Coloproctology

This is an open-access article distributed under the terms of the Creative Commons Attribution NonCommercial License (https://creativecommons.org/licenses/by-nc/4.0) which permits unrestricted noncommercial use, distribution, and reproduction in any medium, provided the original work is properly cited.
Its prevalence has traditionally been underestimated and published data on incidence in the general population vary. For patients treated in a coloproctology unit the most frequent cause is obstetric trauma. Thirteen percent of women develop some degree of incontinence or urgency after their first vaginal delivery [1] and clinical presentation is variable; some patients are symptomatic immediately after delivery and others develop symptoms over time.

FI from obstetric causes is a medical problem that greatly affects patient's quality of life (QoL). Failure of conservative measures to treat patients with anal sphincter injuries often leads to anterior sphincteroplasty, as originally described by Parks and McPartlin [2]. Most series show satisfactory outcomes in approximately $60 \%$ to $80 \%$ of cases [3-6]. However, several studies have shown a substantial clinical deterioration over time $[7,8]$. This worsening of 


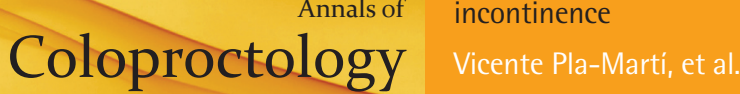

outcomes in the long term has cast doubts on its merit as the technique of choice, in favor of sacral nerve stimulation (SNS) [911].

As previously reported, in our experience sphincteroplasty obtains good results as treatment for obstetric FI (OFI) in a high percentage of patients and has a positive impact on QoL [12]. The main objective of the present study was to evaluate the long-term evolution of continence and analyze its effect on the patient's QoL.

\section{METHODS}

A prospective, longitudinal study spanning 14 years was conducted including consecutive patients who underwent an anterior overlapping sphincteroplasty for OFI. Informed consent was obtained from all individual participants included in the study. The inclusion criterion was severe FI (frequent and inadvertent voiding per anum of formed stools) due to anatomical sphincter injury of obstetric etiology and unresponsive to conservative treatment. Exclusion criteria were primary repair of the sphincter at the time of delivery and patients with severe systemic disease or advanced neoplasia. The following studies were carried out in order to evaluate the functional, clinical, and anatomical aspects of the FI; clinical evaluation, anorectal manometry, anal endosonography (from 1996 on), and measurement of the pudendal nerve terminal motor latency.

Patient data were collected prospectively over the course of the study period. The results analysis was carried out over 2 phases. The first phase analyzed changes in incontinence in patients after surgical treatment and impact on QoL. The second phase studied the long-term evolution of continence and QoL reevaluating the same group of patients 6 years later.

To obtain specific information about their bowel function, patients were given a bowel diary to be completed over 4 weeks. Degree of FI was calculated using the Cleveland Clinic Score (CCS; Fort Lauderdale, FL, USA) [13] where depending on the type of incontinence and the frequency of the episodes, a score from 0 to 20 is obtained, with 0 represents complete continence and 20 the most severe incontinence.

QoL assessment was carried out with the Fecal Incontinence Quality of Life scale (FIQL) developed by Rockwood et al. [14]. The questionnaire consists of 29 questions divided into 4 different scales: lifestyle, coping/behavior, depression/self-perception, and embarrassment. The responses to each are on scale of 1 to 5 , with 1 indicating the worst QoL state. The survey was complete at the end of the 2 phases of the study in all patients. The questionnaire was sent out by mail and performed telephonically where the questionnaire was not received. An independent surgeon not directly involved in patient management conducted the interviews. Patients operated on after the FIQL publication in 2000, completed it also preoperatively.

All patients underwent overlapping anterior sphincteroplasty after mechanical bowel preparation and intravenous antibiotic pro-
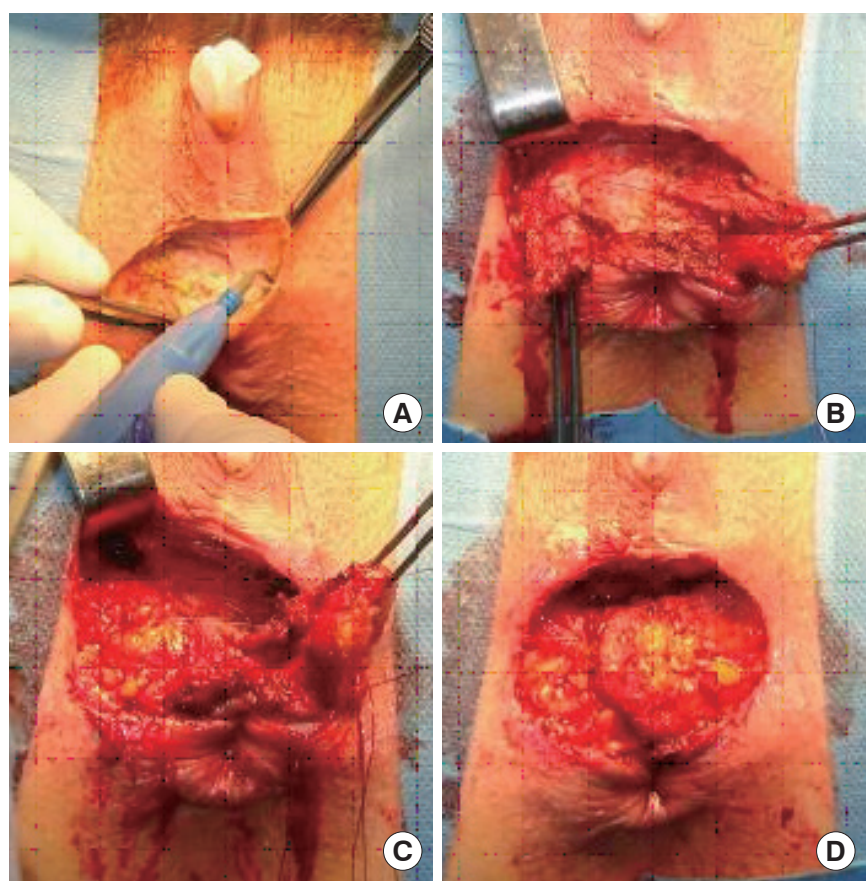

Fig. 1. Surgical technique. (A) Curvilinear incision at the edge of pigmented skin. (B) The 2 ends of the external sphincter have been dissected. (C) The sphincter ends are overlapped suturing the tissue from one end to the middle part of the opposite sphincter muscle. (D) Overlapped anterior sphincteroplasty.

phylaxis [2] (Fig. 1). The same group of dedicated colorectal surgeons performed all surgeries. No derivative stoma was required in any of the cases. In patients with destruction of the central nucleus of the perineum, a Corman's anoplasty was added as a plastic procedure [15]. Surgery indication in patients operated on before endoanal ultrasound was available was based on physical examination. Surgical outcomes were classed as excellent if the CCS showed $>75 \%$ improvement over preoperative status; good, $>50 \%$ and $\leq 75 \%$; fair, $>25 \%$ and $\leq 50 \%$; and poor, for $<25 \%$ improvement.

\section{Statistical methods}

The database manager used different versions of Microsoft Access for Windows (Microsoft, Redmond, WA, USA) and the PASW SPSS Statistics, ver. 18.0 (IBM Corp., Armonk, NY, USA). The quantitative variables studied were preoperative CCS and the scores of the 4 scales of the preoperative QoL survey in phase 1 and 2. The quantitative outcome variables of the study were CCS in the first and second phases. Rothbarth et al. [16] have shown that a CCS score of 9 or above shows a significant deterioration in QoL. On this basis, we discretized the above variables with this value through receiver operating characteristic curve analysis, adopting the cut-off point to maximize sensitivity and specificity. We thus created 2 new qualitative dichotomous variables; CCS 
over 9 in the first and second phases.

Firstly, descriptive statistics of the sample were measured and continuous variables were analyzed using the Shapiro-Wilk normality test. Variables with normal distribution were expressed as mean with standard deviation and the others as median with interquartile range. Qualitative variables were expressed as percentages and absolute frequency.

Possible dependence between quantitative variables was studied using the Spearman coefficient, since these variables did not follow a normal distribution. Correlation between qualitative variables was assessed using the chi-square test. The odds ratio was also calculated when the relationship between the qualitative outcome variables and the study variables was significant $(\mathrm{P}<0.05)$. The relationship between the study variables and the new qualitative outcome variables created was analyzed using the MannWhitney U-test, while the Friedman test was used to compare the CCS scores and the different domains of the QoL survey along the study period. This study has the ethics committee's approval. All procedures performed in the study were conducted according to the ethical standards of the institution and with the $1964 \mathrm{Hel}-$ sinki declaration and later amendments or comparable ethical standards.

\section{RESULTS}

\section{Phase 1 results}

Forty-three patients with a median age of 55 years (range, 28 to 73 years) underwent surgery, of whom 35 (81.4\%) completed the study. Patients' baseline data are shown in Table 1. After a postoperative follow-up of 30 months (4 to 132 months), incontinence had improved significantly from a preoperative CCS of $15.7 \pm 3.1$ to $6.1 \pm 5.0(\mathrm{P}<0.001)$. Excellent outcomes were obtained in $45.7 \%$ of cases, good in $22.9 \%$, fair in $22.9 \%$, and poor in $8.6 \%$. At the end of follow-up, $71.4 \%$ of patients had a CCS over 9 and $14.3 \%$ were totally continent (CCS of 0 ).

The results of the QoL survey in phase 1 of the study were as follows: lifestyle, $3.5 \pm 0.65$; coping/behavior, $3.1 \pm 0.81$; depression/ self-perception, $3.7 \pm 0.75$; and embarrassment, $3.3 \pm 0.91$. Patients with a CCS higher than 9 in this first phase had poorer QoL than those with scores under 9: lifestyle, $2.82 \pm 0.98$ vs. $3.77 \pm 0.31$ $(\mathrm{P}=0.002)$; coping/behavior, $2.26 \pm 0.69$ vs. $3.48 \pm 0.65(\mathrm{P}=0.001)$; depression/self-perception, $3.08 \pm 1.13$ vs. $3.95 \pm 0.37(\mathrm{P}=0.06)$; and embarrassment, $2.15 \pm 0.84$ vs. $3.70 \pm 0.53(\mathrm{P}<0.001)$.

\section{Phase 2 results}

Of the 35 patients who completed phase 1 of the study, we were able to retest $25(71.4 \%)$ in the second. The remaining 10 patients failed to complete the study, due to loss to follow-up in 4 cases, death in 3 , advanced neurological disease in 2, and a final patient was subsequently treated with SNS owing to progression of incontinence (Fig. 2). The median age of the latter group was 54 years (28 to 73 years), and median follow-up in phase 2 was 110
Table 1. Patients' obstetric history and preoperative baseline study data

\begin{tabular}{lc}
\hline Variable & Data \\
\hline Vaginal delivery & $2(1-6)$ \\
Childbirth after onset of incontinence & $16(45.7)$ \\
Risk factors & \\
Instrumental delivery & $12(34.3)$ \\
Birth weight, $>4 \mathrm{~kg}$ & $4(11.4)$ \\
Instrumental \& $>4 \mathrm{~kg}$ & $5(14.3)$ \\
Episiotomy & $5(14.3)$ \\
None & $9(25.7)$ \\
Between childbirth and sphincteroplasty (yr) & $24(1-50)$ \\
Preoperative CCS & $15.5 \pm 3.1$ \\
Manometry (mmHg) & \\
MBP & $25.9 \pm 10.2$ \\
MVCP & $66.7 \pm 25.5$ \\
PNTML & \\
Normal & $23(65.7)$ \\
Pathological & $12(34.3)$ \\
Endoanal ultrasound & $24(68.6)$ \\
EAS injury & \\
Complete & $17(70.8)$ \\
Partial & $7(29.2)$ \\
Degree & $126(60-180)$ \\
\hline
\end{tabular}

Values are presented as median (range), number (\%), or mean \pm standard deviation.

CCS, Cleveland Clinic Score; MBP, maximum basal pressure; MVCP, maximum voluntary contraction pressure; PNTML, pudendal nerve terminal motor latency; EAS, external anal sphincter; IAS, internal anal sphincter.

months (76 to 204 months).

In the group of 25 patients who completed the study, the preoperative CCS had improved significantly in phase 1 of the study, after 30 months follow-up (4 to 132 months), from $15.5 \pm 3.1$ to $5.8 \pm 4.9(\mathrm{P}<0.001)$. In the second phase, a deterioration was observed in the CCS, which lowered to $8.4 \pm 4.9(\mathrm{P}=0.04)$ (Fig. 3). Ten patients (40.0\%) maintained excellent outcomes, good in $4.0 \%$, fair in $24.0 \%$, and poor in $32.0 \%$. Patients who had a CCS below 9 were $60.0 \%$, and $16.0 \%$ were completely continent (CCS of 0 ) (Table 2).

There were no significant differences between phases 1 and 2 in terms of QoL (Fig. 4). Patients who had a CCS greater than 9 in this second phase had worse QoL than those with lower scores: lifestyle, $2.56 \pm 1.25$ vs. $3.65 \pm 0.50$ ( $\mathrm{P}=0.008)$; coping/behavior, $2.15 \pm 1.10$ vs. $3.35 \pm 0.78(\mathrm{P}=0.008)$; depression/self-perception, $2.82 \pm 1.10$ vs. $3.36 \pm 0.67(\mathrm{P}=0.02)$; and embarrassment, $2.61 \pm$ 1.21 vs. $3.56 \pm 0.58(\mathrm{P}=0.03)$. In the 13 patients who completed 
 \\ Coloproctology vicente Pla-Marti, et al.}

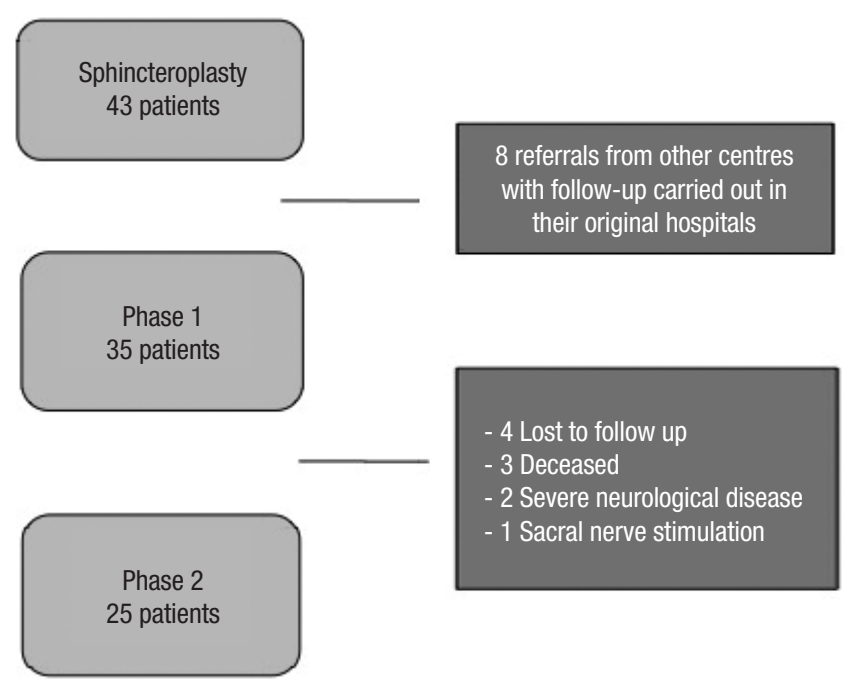

Fig. 2. Distribution of study subjects.

Table 2. Evolution of Cleveland Clinic Score (CCS) between phases 1 and 2 of the study

\begin{tabular}{lcc}
\hline Variable & Phase 1 & Phase 2 \\
\hline CCS & $5.8 \pm 4.9$ & $8.4 \pm 4.9$ \\
Outcome $^{\mathrm{a}}$ & & \\
$\quad$ Excellent & $16(45.7)$ & $10(40.0)$ \\
Good & $8(22.9)$ & $1(4.0)$ \\
Fair & $8(22.9)$ & $6(24.0)$ \\
Poor & $3(8.6)$ & $8(32.0)$ \\
CCS $<9$ & $25(71.4)$ & $15(60.0)$ \\
Completely continent (CCS $=0)$ & $5(14.3)$ & $4(16.0)$ \\
\hline
\end{tabular}

Values are presented as mean \pm standard deviation or number (\%).

amprovement in CCS compared with preoperative score (excellent, > 75\%; good, $>50 \%$ and $\leq 75 \%$; fair, $>25 \%$ and $\leq 50 \%$; and poor, $<25 \%$ ).

the survey preoperatively and were operated afterward, a significant improvement was observed in each of the 4 scales in phase 1 and these results did not get worse in phase 2 (Fig. 5).

\section{DISCUSSION}

OFI is a socially significant and potentially incapacitating condition and treatment should correspond to symptom severity. Conservative measures such as dietary changes, anti-diarrheic agents, or biofeedback techniques are sufficient for lower degrees of FI; but in severe cases, surgical treatment is required. Women with FI have long life expectancy and long-term results should be taken into account when offering treatment. In most series, short-term outcomes with anterior sphincteroplasty of the external anal sphincter are considered excellent or good in $71 \%$ to $86 \%$ of cases [3-6], but studies with a longer-term follow-up of between 5 and

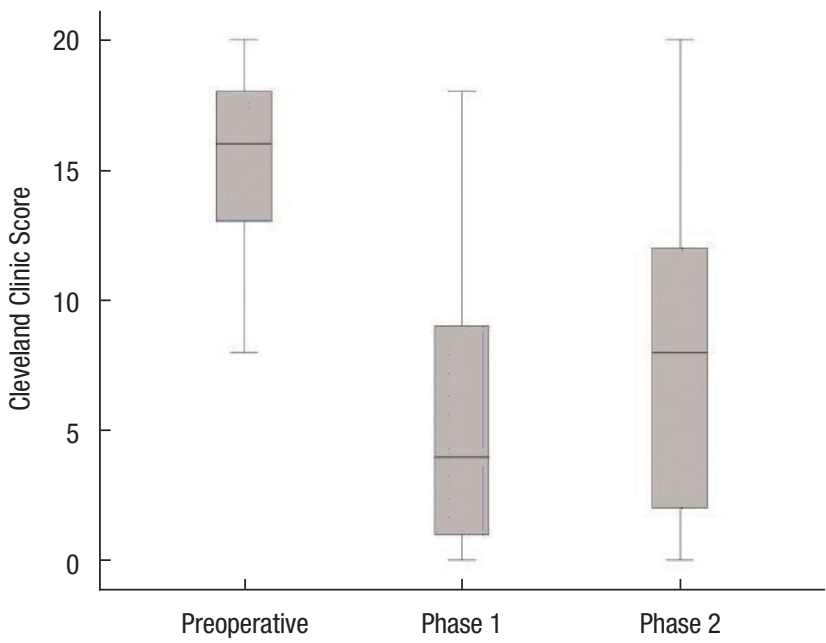

Fig. 3. Box plots showing evolution of continence over time in study subjects. Cleveland Clinic Score was as follows: preoperative, $15.5 \pm 3.1$; phase 1, 5.8 $\pm 4.9(\mathrm{P}<0.001)$; and phase $2,8.4 \pm 4.9(\mathrm{P}=0.04)$.

10 years show worsening continence, indicating that sphincteroplasty loses effectiveness over time [7, 8, 17-19].

Our series is one of the few existing studies with a follow-up of more than 100 months [17, 20, 21]. Consistent with previously mentioned studies, we observed a worsening in patient continence over time; however, we found that satisfactory long-term results were maintained. At 110 months' follow-up, $44 \%$ of patients presented excellent or good outcomes, $56 \%$ had a CCS less than 9 , and $16 \%$ were completely continent. The CCS deteriorated notably in the second phase of the study, although it remained significantly lower compared to before the intervention (8.4 vs. 15.5). Coinciding with our findings, a study of Oom et al. [20] with 111 months' follow-up concludes that sphincteroplasty maintains good or excellent results in the long term in $60 \%$ of patients.

Along the same lines, in a study of OFI patients with 84 months' follow-up, Maslekar et al. [22] note that $20 \%$ remain completely continent, that CCS improved significantly compared with the preoperative period (from 14 to 7 ), and that $95 \%$ of patients were satisfied with the operation. A positive correlation has been found between improvement of sphincter function in the short and long term. Vaizey et al. [23] describe a bimodal distribution; on the one hand, patients with significantly improved continence in the short term and who maintained this in the long term, and on the other patients with poor results from the beginning. In our series, $80 \%$ of patients who showed more than $75 \%$ CCS improvement in the first phase maintained an excellent result in the second.

FI treatment evaluation must take into account not only functional results but whether they improve patients' QoL, and whether this improvement is maintained in the long term. In patients who completed the survey before undergoing surgery, QoL was significantly better in the first phase of the study than before the sphincteroplasty, and this improvement lasted in the long 

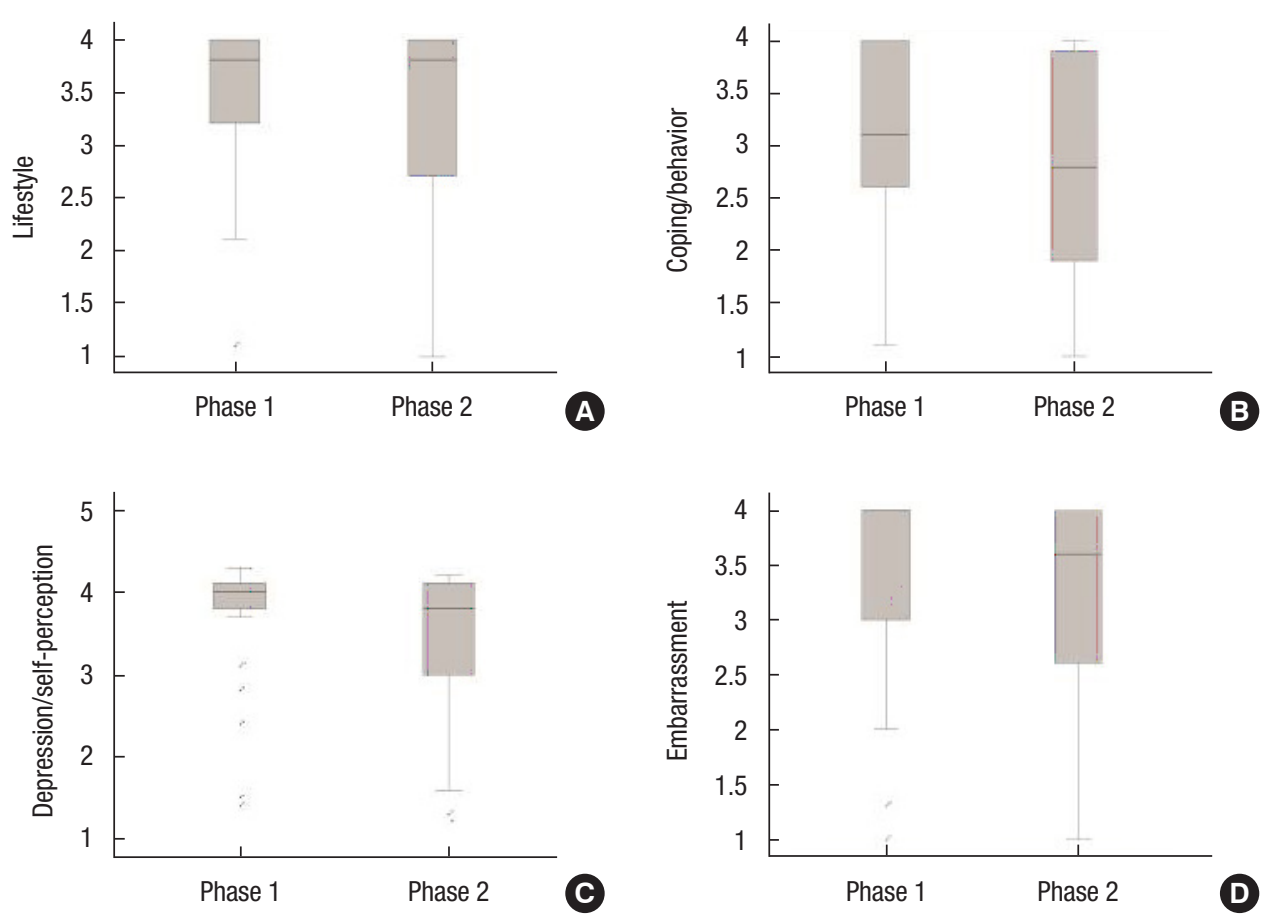

Fig. 4. Box plot comparing scores in phase 1 and 2 of the study across the 4 scales in the quality of life survey. (A) Lifestyle, $3.47 \pm 0.75$ vs. 3.16 $\pm 1.04(\mathrm{P}=0.65)$. (B) Coping/behavior, $3.13 \pm 0.83$ vs. $2.80 \pm 1.09(\mathrm{P}=0.53)$. (C) Depression/self-perception, $3.65 \pm 0.80$ vs. $3.32 \pm 0.98(\mathrm{P}=$ 0.52). (D) Embarrassment, $3.32 \pm 0.9$ vs. $3.12 \pm 1.0(\mathrm{P}=0.10)$.

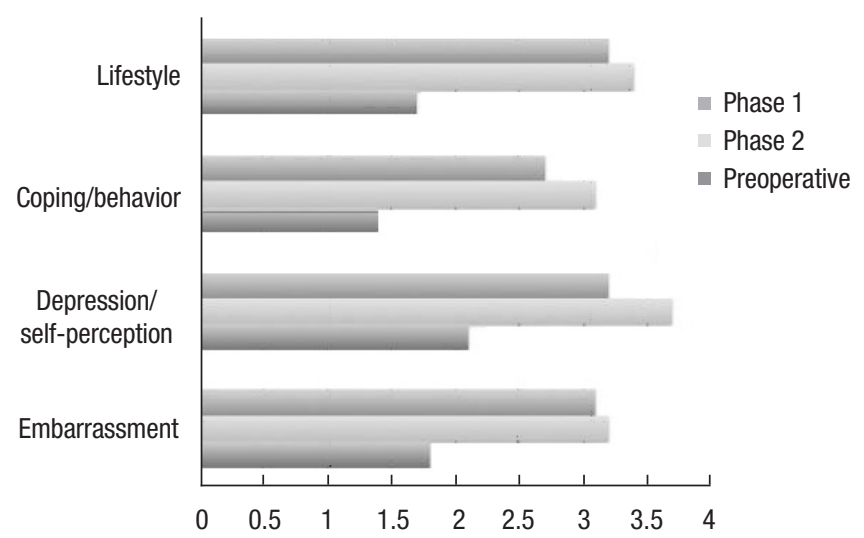

Fig. 5. Scores in Fecal Incontinence Quality of Life scale compared preoperative, phase 1 , and phase 2 of the study. Lifestyle, $1.7 \pm 0.5$ vs. $3.4 \pm 1.0(\mathrm{P}=0.001)$; vs. $3.2 \pm 1.0(\mathrm{P}=0.64)$. Coping/behavior, $1.4 \pm 0.3$ vs. $3.1 \pm 0.8(\mathrm{P}=0.001)$; vs. $2.7 \pm 1.0(\mathrm{P}=0.20)$. Depression/self-perception, $2.1 \pm 0.7$ vs. $3.7 \pm 0.8(\mathrm{P}=0.001)$; vs. $3.2 \pm 1.0(\mathrm{P}=0.17)$. Embarrassment, $1.8 \pm 0.7$ vs. $3.2 \pm 1.0(\mathrm{P}=0.001)$; vs. $3.1 \pm 1.0(\mathrm{P}=0.29)$.

term. Likewise, when analyzing the complete series, we observed that results obtained in the QoL survey in the first phase did not change over time, despite deterioration in continence. The cut-off point (CCS of 9) described by Rothbarth et al. [16] was validated, as in both the first and second phases women with a CCS under 9 had better QoL results than those scoring 9 or over. CCSs remained below 9 at the end of follow-up, showing no significant changes in QoL.

Nowadays SNS plays a very important role in therapeutic algorithms for FI [24, 25]. Recent studies have reported successful outcomes with SNS in patients with sphincter trauma, prompting debate on whether sphincteroplasty should remain the technique of choice [9-11]. The long-term data available, however, indicate that there may also be deterioration in continence after SNS [26, 27]. Likewise, SNS effectiveness may be overestimated in some studies that analyze the number of patients with definitive implant with 50\% reduction in incontinence at the end of follow-up, without considering patients in whom the device was not implanted owing to treatment failure at the initial trial phase. When all patients intended for treatment are included in the analysis response rates range between $40 \%$ and $60 \%$, with an average of 59\% vs. $85 \%$ when only patients with an installed neuromodulator are studied [28].

Several factors complicate comparative analysis of SNS and sphincteroplasty outcomes in published series; heterogeneity, low patient numbers, lack of uniform criteria for success, and diverse methodology used to evaluate outcomes in terms of postoperative continence and patient satisfaction. The limited number of studies that compare both techniques are therefore retrospective and with few patients $[29,30]$. To clarify the true role of each in OFI management, long-term prospective and randomized studies are 


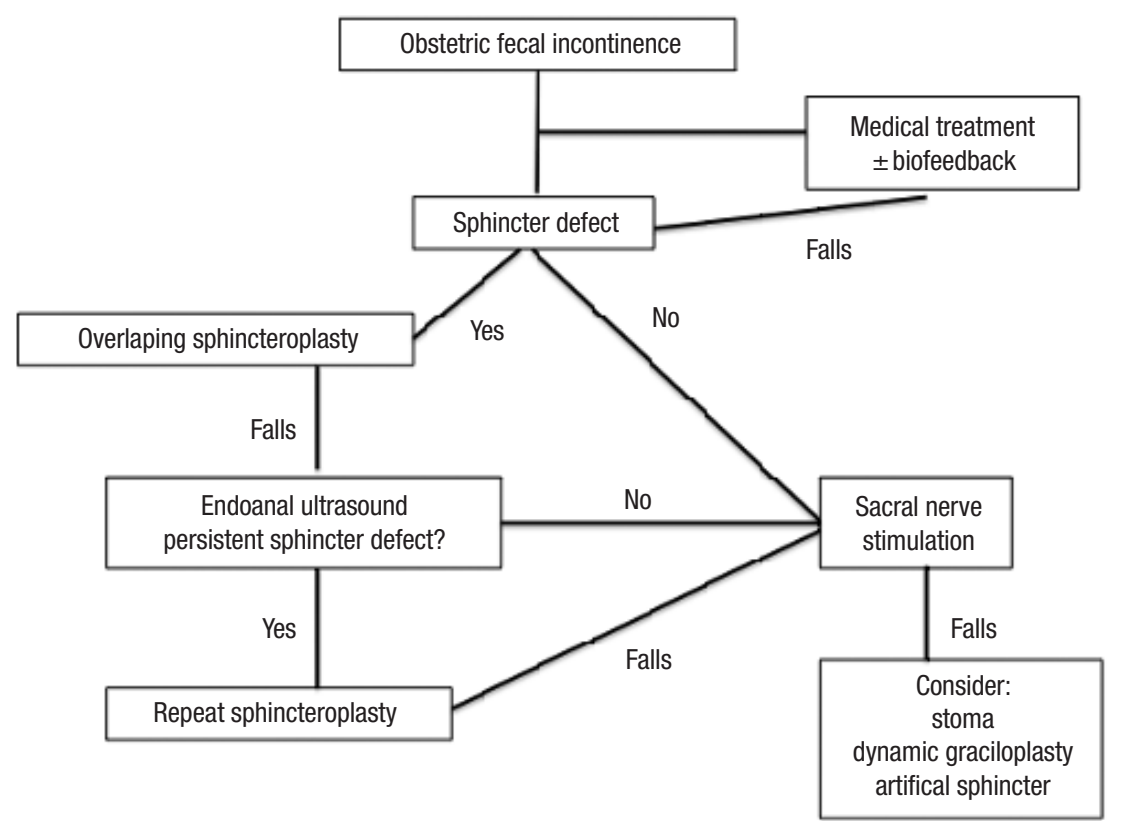

Fig. 6. Obstetric fecal incontinence surgical treatment algorithm.

needed, including only patients with this etiology, comparing SNS and sphincteroplasty using severity scales and validated QoL surveys. Our treatment of choice in patients with obstetric fecal incontinence and shincter defect is sphincteroplasty (Fig. 6).

Finally, this study is limited by certain factors. Firstly, the patient inclusion period was extensive; availability of diagnostic tools such as endoanal ultrasound or QoL questionnaire varied during this time. In the initial analysis during the first phase of the study, there was marked heterogeneity regarding time elapsed since sphincteroplasty and the follow-up range was therefore very broad. Another hindrance was the limited number of patients, which as expected in a long-term longitudinal study was exacerbated by loss to follow-up. Lastly, this study analyses outcomes of a specific surgical technique without comparison with other treatments. Despite these limitations, we think that our work makes an interesting contribution, being 1 of the few series in the literature with a follow-up of over 100 months, which analyses the evolution of continence and QoL in FI patients of obstetric origin.

In conclusion, anterior sphincteroplasty offers good short-medium term outcomes for OFI treatment and this improvement has a positive impact on patients' QoL. Functional clinical results deteriorate over time but remain good in a high percentage of patients. Long term deterioration in fecal continence did not impact on patients' QoL.

\section{CONFLICT OF INTEREST}

No potential conflict of interest relevant to this article was reported.

\section{REFERENCES}

1. Sultan AH, Kamm MA, Hudson CN, Thomas JM, Bartram CI. Anal-sphincter disruption during vaginal delivery. N Engl J Med 1993;329:1905-11.

2. Parks AG, McPartlin JF. Late repair of injuries of the anal sphincter. Proc R Soc Med 1971;64:1187-9.

3. Engel AF, Kamm MA, Sultan AH, Bartram CI, Nicholls RJ. Anterior anal sphincter repair in patients with obstetric trauma. Br J Surg 1994;81:1231-4.

4. Buie WD, Lowry AC, Rothenberger DA, Madoff RD. Clinical rather than laboratory assessment predicts continence after anterior sphincteroplasty. Dis Colon Rectum 2001;44:1255-60.

5. Karoui S, Leroi AM, Koning E, Menard JF, Michot F, Denis P. Results of sphincteroplasty in 86 patients with anal incontinence. Dis Colon Rectum 2000;43:813-20.

6. Young CJ, Mathur MN, Eyers AA, Solomon MJ. Successful overlapping anal sphincter repair: relationship to patient age, neuropathy, and colostomy formation. Dis Colon Rectum 1998;41:344-9.

7. Halverson AL, Hull TL. Long-term outcome of overlapping anal sphincter repair. Dis Colon Rectum 2002;45:345-8.

8. Fornell EU, Matthiesen L, Sjödahl R, Berg G. Obstetric anal sphincter injury ten years after: subjective and objective long term effects. BJOG 2005;112:312-6.

9. Jarrett ME, Dudding TC, Nicholls RJ, Vaizey CJ, Cohen CR, Kamm MA. Sacral nerve stimulation for fecal incontinence related to obstetric anal sphincter damage. Dis Colon Rectum 2008; 51:531-7.

10. Brouwer R, Duthie G. Sacral nerve neuromodulation is effective 
treatment for fecal incontinence in the presence of a sphincter defect, pudendal neuropathy, or previous sphincter repair. Dis Colon Rectum 2010;53:273-8.

11. Boyle DJ, Knowles CH, Lunniss PJ, Scott SM, Williams NS, Gill KA. Efficacy of sacral nerve stimulation for fecal incontinence in patients with anal sphincter defects. Dis Colon Rectum 2009;52: 1234-9.

12. Pla-Martí V, Moro-Valdezate D, Alos-Company R, Solana-Bueno A, Roig-Vila JV. The effect of surgery on quality of life in patients with faecal incontinence of obstetric origin. Colorectal Dis 2007; 9:90-5.

13. Jorge JM, Wexner SD. Etiology and management of fecal incontinence. Dis Colon Rectum 1993;36:77-97.

14. Rockwood TH, Church JM, Fleshman JW, Kane RL, Mavrantonis C, Thorson AG, et al. Fecal incontinence quality of life scale: quality of life instrument for patients with fecal incontinence. Dis Colon Rectum 2000;43:9-16.

15. Corman ML. Anal incontinence following obstetrical injury. Dis Colon Rectum 1985;28:86-9.

16. Rothbarth J, Bemelman WA, Meijerink WJ, Stiggelbout AM, Zwinderman AH, Buyze-Westerweel ME, et al. What is the impact of fecal incontinence on quality of life? Dis Colon Rectum 2001;44:67-71.

17. Bravo Gutierrez A, Madoff RD, Lowry AC, Parker SC, Buie WD, Baxter NN. Long-term results of anterior sphincteroplasty. Dis Colon Rectum 2004;47:727-31.

18. Rothbarth J, Bemelman WA, Meijerink WJ, Buyze-Westerweel ME, van Dijk JG, Delemarre JB. Long-term results of anterior anal sphincter repair for fecal incontinence due to obstetric injury: with invited commentaries. Dig Surg 2000;17:390-3.

19. Glasgow SC, Lowry AC. Long-term outcomes of anal sphincter repair for fecal incontinence: a systematic review. Dis Colon Rectum 2012;55:482-90.

20. Oom DM, Gosselink MP, Schouten WR. Anterior sphincteroplasty for fecal incontinence: a single center experience in the era of sacral neuromodulation. Dis Colon Rectum 2009;52:1681-7.
21. Zutshi M, Tracey TH, Bast J, Halverson A, Na J. Ten-year outcome after anal sphincter repair for fecal incontinence. Dis Colon Rectum 2009;52:1089-94.

22. Maslekar S, Gardiner AB, Duthie GS. Anterior anal sphincter repair for fecal incontinence: good longterm results are possible. J Am Coll Surg 2007;204:40-6.

23. Vaizey CJ, Norton C, Thornton MJ, Nicholls RJ, Kamm MA. Long-term results of repeat anterior anal sphincter repair. Dis Colon Rectum 2004;47:858-63.

24. Vallet C, Parc Y, Lupinacci R, Shields C, Parc R, Tiret E. Sacral nerve stimulation for faecal incontinence: response rate, satisfaction and the value of preoperative investigation in patient selection. Colorectal Dis 2010;12:247-53.

25. Abrams P, Andersson KE, Birder L, Brubaker L, Cardozo L, Chapple C, et al. Fourth international consultation on incontinence recommendations of the International Scientific Committee: evaluation and treatment of urinary incontinence, pelvic organ prolapse, and fecal incontinence. Neurourol Urodyn 2010;29: 213-40.

26. Altomare DF, Giuratrabocchetta S, Knowles $\mathrm{CH}$, Muñoz Duyos A, Robert-Yap J, Matzel KE, et al. Long-term outcomes of sacral nerve stimulation for faecal incontinence. Br J Surg 2015;102:40715.

27. Matzel KE. Sacral nerve stimulation for faecal incontinence: its role in the treatment algorithm. Colorectal Dis 2011;13 Suppl 2:10-4.

28. Chiarioni G, Palsson OS, Asteria CR, Whitehead WE. Neuromodulation for fecal incontinence: an effective surgical intervention. World J Gastroenterol 2013;19:7048-54.

29. Ratto C, Litta F, Parello A, Donisi L, Doglietto GB. Sacral nerve stimulation is a valid approach in fecal incontinence due to sphincter lesions when compared to sphincter repair. Dis Colon Rectum 2010;53:264-72.

30. Rodrigues FG, Chadi SA, Cracco AJ, Sands DR, Zutshi M, Gurland $\mathrm{B}$, et al. Faecal incontinence in patients with a sphincter defect: comparison of sphincteroplasty and sacral nerve stimulation. Colorectal Dis 2017;19:456-61. 